\title{
Sangre, intriga y materialismo dialéctico: notas sobre el teatro policiaco y de contraespionaje cubano ${ }^{1}$
}

\author{
Emilio José Gallardo Saborido
}

Escuela de Estudios Hispano-Americanos. CSIC

\begin{abstract}
Esta contribución pretende ofrecer un primer acercamiento a un corpus que ha sido escasamente considerado por la crítica: la producción dramática cubana policiaca o de contraespionaje. Nacidos al calor del éxito de la narrativa y la novela, estos textos se produjeron básicamente a lo largo de la década de 1970 y principios de la de 1980. En ellos se aprecia la imbricación entre ideología y literatura que caracterizó a buena parte de la producción cultural cubana del periodo mencionado. Se presta especial atención a los dramas Ha muerto una mujer, Ernesto y Aquí del G-2 soy yo (todos ellos de Gerardo Fernández García) y a Crimen en Noche de máscaras, obra de Antonio Veloso y Rodolfo Pérez Valero.
\end{abstract}

PALABRAS CLAVE: teatro cubano, novela negra, cultura de masas, ideología, socialismo.

This essay intends to offer a first approach to some works that have been rarely taken into account by literary criticism: Cuban crime and contraspying theatre. These texts were mainly produced in the 70s and early 80s due to the success of the novels dealing with the same topics. They clearly show the link between literature and ideology that was the core of the an important part of Cuban cultural production of the period. Some plays are specially dealt with Ha muerto una mujer, Ernesto y Aquí del G-2 soy yo by Gerardo Fernández García and Crimen en Noche de máscaras, by Antonio Veloso y Rodolfo Pérez Valero.

Keywords: Cuban Theatre. Crime Novel. Mass Culture. Ideology, Socialism.

\section{Del asesinato considerado como una de las bellas artes: introducción}

El interés primordial de esta contribución reside en presentar una aproximación a un determinado grupo de dramas que surgieron al calor del

1 Esta contribución fue presentada en el XIII Encuentro de Latinoamericanistas Españoles (Castellón, 2008) en el área temática "Conflicto bélico-conflicto ideológico: la propaganda política en tiempos de guerra", coordinada por J. Raúl Navarro. La preparación de este artículo ha sido posible gracias al apoyo del Proyecto de Excelencia de la Consejería de Innovación, Ciencia y Empresa de la Junta de Andalucía, titulado "Andalucía y América Latina: intercambios y transferencias culturales". 
éxito de la novela policiaca y de contraespionaje cubana. Aunque hermanadas con las manifestaciones narrativas, estas producciones han gozado en escasas ocasiones de la atención de la crítica, sobre todo internacional. Sirva este artículo para ofrecer unos primeros tanteos sobre el asunto, apuntando además la relevancia socio-crítica de este tipo de obras teatrales.

La Cuba de inicios de la década de 1970 ofrecía un panorama político cultural ideal para que se estimulara la aparición y desarrollo de las tendencias artísticas que incidieran especialmente en lo ideológico. Denominado por Ambrosio Fornet como el "Quinquenio Gris", el periodo que va desde 1971 hasta 1976 constituye una fase de la reciente historia literaria del país que vio cómo se producía lo que en términos bourdeausianos etiquetaríamos como una heteronormativización paradigmática. Esto es, la dinámica interna del campo artístico se plegó comúnmente a las directrices emanadas desde otros campos (el político, sobre todo), haciendo que se favoreciesen los productos culturales que imbricaban sus intereses creativos con otros de índole social, ideológica, política, etc. El "Quinquenio Gris" se desarrolló enmarcado entre ciertos acontecimientos claves en el devenir de la política cultural revolucionaria, como pudieron ser el tajante I Congreso Nacional de Educación y Cultura (1971) y la creación del Ministerio de Cultura (MINCULT), a cuyo frente se destinó a Armando Hart en 1976; al tiempo que la cultura estuvo dirigida desde el Consejo Nacional de Cultura (CNC), de Luis Pavón. Una de las consignas que mejor pueden definir a esta etapa es la divisa que adoptó el Grupo de Teatro Escambray: "Hacer del teatro un arma de la Revolución".

Dentro de las corrientes narrativas del momento empieza a hacerse notar la de corte policial. Aunque se podían rastrear precedentes en la historia literaria nacional, se considera que Enigma para un domingo (1971), de Ignacio Cárdenas Acuña, supone el hito fundacional clave, por lo menos después de 1959. Este tipo de literatura tendrá sus ejemplos más logrados en títulos como No es tiempo de ceremonias (1974), de Rodolfo Pérez Valero, La ronda de los rubíes (1974), de Armando Cristóbal Pérez, Los hombres color del silencio (1975), de Alberto Molina, El cuarto círculo (1976), de Guillermo Rodríguez Rivera y Luis Rogelio Nogueras, Joy (1977), de Daniel Chavarría, o en Y si muero mañana (1978), de Luis Rogelio Nogueras. La narrativa policial y de contraespionaje nacida en el seno de la Revolución no se limitó a revisar los modelos creativos que ofrecía la historia del género, ya fueran los provenientes de la escuela de enigmas matemáticamente distinguidos a lo Arthur Conan Doyle o Agatha 
Christie, ya se hermanaran con la negrura depresiva de un Dashiell Hammet o de un Raymond Chandler. Al contrario, supo adaptar las técnicas y los temas propios del género a las exigencias de un campo cultural heteronormativo, al propósito de divertir adoctrinando. Para decirlo con palabras del profesor de estética José Antonio Portuondo: "la novela [policial cubana] mantiene los rasgos esenciales del género, pero trae este nuevo sentido de identificación de justicia y legalidad socialistas y, sobre todo, el concepto de realización colectiva, como autodefensa del nuevo orden social revolucionario". ${ }^{2}$ Es decir, se pretendía ofrecer una sublimación ideo-moral, tal y como la definía el crítico Desiderio Navarro. ${ }^{3}$

De este modo, los rasgos esenciales que otorgan a estas creaciones su impronta característica han sido sintetizados por diversos creadores como, por ejemplo, Armando Cristóbal ("El género policial cubano y la lucha de clases: un reto para los escritores revolucionarios") o Luis Rogelio Nogueras y Guillermo Rodríguez Rivera ("¿La verdadera novela policial?"). ${ }^{4}$ Algunas de estas señas de identidad serían:

En primer lugar, el peso de la heroicidad propuesta recae sobre el cuerpo policial en su conjunto, superando el individualismo de aficionados brillantes o detectives exitosos. ${ }^{5}$ Junto a la policía, colaboran determinados individuos pertenecientes a organizaciones de masa como los Comités de Defensa de la Revolución (CDR), intentando patentizar así la comunión de intereses entre el pueblo y los cuerpos de seguridad, unidos ambos en su deseo por mantener y resguardar el estado socialista de los ataques de los delincuentes comunes o políticos. Bajo este enfoque, todo crimen, sean cuales sean sus características, supone un ataque a la hegemonía socialista, por lo que en cierto grado es susceptible de convertirse en un delito políti-

2 Portuondo, José Antonio: "La novela policial revolucionaria”, en Portuondo, José Antonio: Astrolabio, Arte y Literatura, La Habana, 1973, pág. 130.

3 Navarro, Desiderio: A pe(n)sar de todo. Para leer en contexto, Letras Cubanas, La Habana, 2007, pág. 236.

4 Cristóbal, Armando: "El género policial cubano y la lucha de clases: un reto para los creadores”, y Nogueras, Luis Rogelio y Rodríguez Rivera, Guillermo: “La verdadera novela policial?”. Ambos en Nogueras, Luis Rogelio (selección y prólogo): Por la novela policial, Arte y Literatura, La Habana, 1982, págs. 298-305 y 137-153, respectivamente.

5 El profesor Rodríguez Coronel opinaba lo que sigue sobre la importancia de que los roles protagónicos se tornen colectivos en la novela de espionaje: "Por supuesto, que contamos con acciones individuales heroicas, y deben ser tomadas en cuenta, pero el camino de la novela cubana de espionaje se esboza dentro del enriquecimiento de la relación que se establece entre individuo y empresa colectiva, entre los valores que surgen de una conciencia social y su repercusión —y también contradicción no antagónica - en la conciencia individual" (Rodríguez Coronel, Rogelio: Novela de la revolución y otros temas, Letras Cubanas, La Habana, 1983, pág. 71). 
co, a pesar de tratarse, por ejemplo, de un simple hurto. ${ }^{6}$ No obstante, es el delito político aquel que da lugar a las creaciones de contraespionaje, puesto que en ellas el oponente del estado socialista pretende derrocar al orden imperante con o sin la ayuda de potencias extranjeras.

Otra característica que Armando Cristóbal otorga a este tipo de narraciones reside en rehuir el empleo de los elementos más sórdidos de la novela negra norteamericana, de modo que considera inadecuado destacar, por ejemplo, el sexo o la violencia por sí mismos. Cristóbal sostiene que utilizar estos recursos atentaría contra la representación fiel de la nueva sociedad. De ahí se desprende que el autor revolucionario ha de buscar nuevos medios creativos en sintonía con el contexto socialista en el que vive. ${ }^{7}$ A este respecto, una diferencia clara entre la novela de espionaje de ideología capitalista y la de los países socialistas reside en el realismo requerido a la segunda. Rogelio Rodríguez Coronel $^{8}$ ha insistido en este punto que distanciaría a los métodos de cuerpos como el servicio secreto cubano, el G-2, de la tendencia a la ciencia-ficción que rodea a sagas como la de James Bond, de Ian Fleming (ex-oficial de Inteligencia Naval de la Marina Real británica), propensión en la que, por cierto, reside una parte considerable de su éxito comercial. No obstante, este afán realista no ha estado ajeno a las críticas:

No pocas veces se ha escrito sobre un pretendido realismo dentro de la novela policial autóctona que, a derechas, es falso. Una ojeada al mundo presentado que estructuran esas obras pone en claro que no van de lo particular a lo general, de lo concreto a lo abstracto, para aprehender la zona de la vida que les sirve de base; más bien recorren el trayecto inverso: parten de determinadas premisas ideológicas, éticas y políticas para llegar a la realidad concreta, lo cual provoca que el resultado literario, como señalaba Desiderio Navarro en la cita del principio, se acerque al género de la fábula. $\mathrm{O}$, para ser explícitos, que esa realidad sea manipulada con el fin de corroborar diáfanamente las tesis que sirvieron al autor de punto de partida, y esto hace del texto un ámbito descomplejizado, reducido al papel de ilustración propagandística. ${ }^{9}$

Sea como sea, lo policiaco se convirtió en poco tiempo en Cuba en un fenómeno de cultura de masas. Los datos resultan bastante elocuentes: se

6 "En la práctica puede decirse que un delito común es también una manifestación contrarrevolucionaria". Nogueras, Por la novela policial, pág. 305.

7 Cristóbal, "El género policial", págs. 302-303.

8 Rodríguez Coronel, Novela, págs. 68, 70. pág. 48.

9 Fernández Pequeño, José M.: Crítica sin retroceso, Ediciones Unión, La Habana, 1994b, 
produjo un ascenso de las tiradas de autores cubanos y extranjeros que cultivaban este género hasta llegar a los cincuenta mil ejemplares por título, que, por otro lado, solían agotarse a los tres días de venta, de ahí que no resultaran extrañas las reediciones. ${ }^{10}$ Asimismo, gracias al éxito de la novela y el relato se favoreció la presencia de lo policiaco en otros medios como la radio, la televisión, el cómic o el teatro.

Umberto Eco sintetiza en Apocalípticos e integrados algunas de las "acusaciones principales" que se han sustentado en contra de la cultura de masas:

"Los mass media tienden a imponer símbolos y mitos de fácil universalidad, creando 'tipos' reconocibles de inmediato, y con ello reducen al mínimo la individualidad y la concreción de nuestras experiencias y de nuestras imágenes, a través de las cuales deberíamos realizar experiencias".

[...]

"Para realizar esto, trabajan sobre opiniones comunes, sobre los endoxa, y funcionan como una continua reafirmación de lo que ya pensamos. En tal sentido desarrollan siempre una acción socialmente conservadora".

[...]

"Se desarrollan pues, incluso cuando fingen despreocupación, bajo el signo del más absoluto conformismo, en la esfera de las costumbres, de los valores culturales, de los principios sociales y religiosos, de las tendencias políticas. Favorecen proyecciones hacia modelos 'oficiales".."1

Si bien estos asertos pueden corresponderse con mayor o menor exactitud con lo ocurrido con las producciones policiacas o de espionaje en Cuba, no parece aplicable a las mismas esta nueva afirmación: "Los mass media alienan así una visión pasiva y acrítica del mundo. El esfuerzo personal para la posesión de una nueva experiencia queda desalentado". ${ }^{12}$ Más bien, la profunda carga ideológica que conllevaban estas creaciones fomentaban la toma de conciencia socialista y la llamada a una puesta en guardia de las mentes y los cuerpos a fin de evitar cualquier tipo de crimen, "diversionista" o no. ${ }^{13}$ Hasta tal punto el poder político y militar se convenció de

10 Navarro, A pe(n)sar, pág. 233.

11 Eco, Umberto: Apocalípticos e integrados, Tusquets, Barcelona, 2003, págs. 58- 59.

12 Ibídem, pág. 58.

13 El diccionario de la RAE en su versión digital (www.rae.es) ofrece una acepción para "diversión" que aclara el matiz ideológico-militar con el que derivados como "diversionismo" o "diversionista" se han usado en la Cuba revolucionaria. La entrada reza así: "Mil. Acción de distraer o desviar la atención y fuerzas del enemigo". 
la utilidad de este tipo de literatura como modo de alentar el patriotismo revolucionario que, ya en 1971, tan sólo un año después de la aparición de Enigma para un domingo, la Dirección Política del Ministerio del Interior convocaba el Concurso Aniversario del Triunfo de la Revolución. En 1973, la revista Revolución y Cultura entrevistó al responsable de Cultura del Ministerio del Interior, el teniente Jorge Boullón, quien resumía con estas palabras los objetivos y experiencias del certamen:

\begin{abstract}
Este certamen, cuya finalidad — como recogen sus bases— es estimular la prevención de los delitos antisociales o contra el poder del pueblo, se organizó por primera vez en 1971. Nuestro organismo estaba interesado en abrir un nuevo conducto de expresión a la literatura revolucionaria. En aquella ocasión, tuvo un carácter interno; es decir, sólo contó con la participación de los combatientes del MININT [Ministerio del Interior] y de las FAR [Fuerzas Armadas Revolucionarias]. Esta medida respondió al propósito de ganar experiencias en eventos de esta naturaleza, así como en la promoción del género policial. ${ }^{14}$
\end{abstract}

Así pues, se observa cómo el carácter didáctico requerido a las obras presentadas era uno de los elementos claves que entraban en juego a la hora de otorgar el lauro o no a un determinado texto. ${ }^{15}$ Gracias a este tipo de prácticas se aprecia cómo se fomentó la identificación entre varios de los elementos que Terry Eagleton definió en Criticism and Ideology como propios de la teoría marxista de la literatura, esto es: se producía un acercamiento propiciado por el propio poder gubernamental entre general ideology, authorial ideology, aesthetic ideology y el propio texto. ${ }^{16}$ En este sentido, la producción policiaca actuó como una forma artística privilegiada, donde se evidenció paradigmáticamente el carácter heteronormativo del campo cultural de la época. Precisamente, y debido a este énfasis en el contenido ideológico, este tipo de creaciones ha sufrido a la postre la crítica de ciertos investigadores que han considerado que se llegó a abandonar en demasiadas ocasiones la calidad literaria en favor del compromiso político. De este modo, José M. Fernández Pequeño resume las que tiene por sus debilidades más acusadas, que se habrían hecho más patentes sobre todo a partir de 1979:

14 Boullón, Jorge: "Un arma ideológica de la Revolución. La narrativa policiaca", Revolución y Cultura, La Habana, 1973, n. ${ }^{\circ} 15$, pág. 16.

15 "Convocatoria al concurso Aniversario de la Revolución. Género policiaco. Diciembre del 72. MININT”, La Gaceta de Cuba, La Habana, 1972, n. ${ }^{o}$ 106, pág. 24.

16 Eagleton, Terry: Criticism and Ideology, Verso, London, 1980. 
1. Investigadores planos, apenas individualizados, que mantienen entre sí relaciones paradisíacas y cuyo único vínculo con el delito se registra en lo referente a la ideología.

2. Cederistas afables, milimétricamente informados.

3. Delincuentes inescrupulosos, llenos de dobleces y ambiciones, que con frecuencia llegan a la estupidez, pero cuyo universo, por conflictivo, resulta siempre más convincente que el descomplejizado en que se mueven los investigadores.

4. Un cierto costumbrismo - formas de hablar, el humor criollo, hábitos idiosincrásicos, etc. - para reafirmar el sello nacional de la novela. ${ }^{17}$

\section{A estas críticas habría que sumar las realizadas por Desiderio} Navarro, quien sostiene que:

La novela policial ha adquirido rasgos que la asemejan al género de la fábula: los elementos del plano del sujet asumen la función de ilustrar tesis o valoraciones; las enseñanzas resultan del contraste entre dos actitudes, conductas o argumentaciones; los personajes no son figuras individualizadas, irrepetibles, sino simples portadores de ciertos rasgos típicos; y las formas básicas de manifestación de la ideología en la obra son la mencionada ilustración fabular y la declaración directa del autor o de su porte-parole o raisonneur. Lo simple, lo fácil y lo conocido para la mayor cantidad de público prolongan su dominio en las nuevas obras lúdico-didácticas. ${ }^{18}$

\section{En cuanto a los factores externos que habrían contribuido a llegar a} esta situación, Fernández Pequeño sentencia:

1. Edición indiscriminada y en grandes volúmenes de este tipo de literatura nacional. Entre 1980 y 1983 se imprimieron 22 novelas policiales cubanas. Esa falta de rigor editorial otorgó el honor de las prensas a textos febles, incluso desastrosos.

2. La ausencia de una auténtica crítica en torno a la literatura policial revolucionaria, rodeada en los años setenta de un barraje promocional que, salvo contadísimas excepciones, se dedicó a exaltar sus posibilidades o a batir palmas frente a las novelas que se iban publicando. Estudios críticos globales y seriamente orientados hacia esta literatura en Cuba no se publicaron hasta la segunda mitad de los años ochenta.

3. La cuidadosa vigilancia con que fueron observados los presupuestos ideológicos y los medios para conseguirlos que habían acompañado en su nacimiento a la literatura policial revolucionaria, lo cual no sólo se hizo evidente en la censura a novelas portadoras de una visión crítica hacia alguna estructura oficial cubana, sino también a obras que ensayaban cualquier cambio dentro de los esquemas palmariamente ideológicos canonizados por esta literatura.

4. El concurso Aniversario de la Revolución que, rigiéndose por iguales principios, premió en el periodo varios libros de bien escasa calidad. ${ }^{19}$

17 Fernández Pequeño, José M.: Cuba: la narrativa policial entre el querer y el poder (1973-

1988), Editorial Oriente, Santiago de Cuba, 1994, pág. 17.

18 Navarro, A pe(n)sar, pág. 238.

19 Fernández Pequeño, Cuba, pág. 20. 
Tras esta introducción general centrada en la narrativa, pasemos a centrarnos en la materia específica de análisis, esto es, la producción dramática policiaca o de contraespionaje. Si bien constituyen un grupo poco nutrido de obras y su repercusión en la historia teatral cubana a posteriori no es demasiado significativa, su importancia crece si consideramos su valor socio-crítico, como reflejo que son de un momento muy particular de la literatura cubana, donde ideología y literatura estrecharon sus lazos. Del mismo modo, profundizar en este tipo de estudios ofrece la posibilidad de ahondar en un terreno que quizás no se haya considerado como debiera a la hora de trabajar sobre la denominada "cultura de masas". Me refiero al desarrollo de este tipo de discursos y productos en los países socialistas. De este modo, al decir "cultura de masas" los investigadores afincados en países de tradición capitalista solemos pensar casi automáticamente en figuras como Superman, Rambo o Madonna, dejando de lado fenómenos tan interesantes como la animación soviética, la Nueva Trova o la narrativa de ciencia-ficción de cuño socialista, por poner tan sólo unos ejemplos.

\section{Los escenarios y las siluetas de tiza (roja)}

El corpus que tendré en consideración está compuesto por los siguientes textos: Ha muerto una mujer (estrenado en el teatro Mella por el Grupo de Teatro Político Bertolt Brecht en 1976), de Gerardo Fernández García; Crimen en "Noche de máscaras" (premio de teatro del concurso Aniversario del Triunfo de la Revolución, Ministerio del Interior o MININT, 1981), de Antonio Veloso y Rodolfo Pérez Valero; Ernesto (estrenado en el teatro Mella por el Grupo de Teatro Político Bertolt Brecht en 1976), de Gerardo Fernández García; Aquí del G-2 soy yo (1981), del mismo autor. Las dos primeras obras se encuadran dentro de la variedad policiaca, las dos últimas dentro del teatro de contraespionaje. ${ }^{20}$

Como se habrá apreciado, fue Gerardo Fernández García (1932) el dramaturgo que se preocupó especialmente por impulsar este tipo de líneas creativas, constituyendo una parte significativa de su propia producción, donde también encontramos creaciones de otras características como

20 He aquí las referencias de las obras analizadas: Fernández García, Gerardo: Ernesto y Ha muerto una mujer, Letras Cubanas, La Habana, 1979; y Aquí del G-2 soy yo, Ediciones Unión, La Habana, 1981; Veloso, Antonio y Pérez Valero, Rodolfo: Crimen en "Noche de máscaras", Letras Cubanas, La Habana, 1989. 
La perra (mención Concurso David '74), La familia de Benjamín García o Mónica, que, según el crítico y dramaturgo Amado del Pino, se centran en "las disyuntivas del hombre ante circunstancias, casi siempre sorpresivas, que ponen a prueba su postura ética". ${ }^{21}$ Es más, Fernández García se había interesado previamente por el género policiaco y de contraespionaje al escribir guiones radiofónicos para programas como Sector 40 o Agente Especial. Incluso, al estrenarse Hа mиerto una mujer, un crítico anunciaba que cabría la posibilidad de que el Instituto Cubano de Radiodifusión (ICR) difundiera por televisión la dramaturgia de este autor a través de grabaciones de las representaciones..$^{22}$ Así pues, Fernández García, gracias a su pieza Ha muerto una mujer, merece ser considerado como el iniciador de la vertiente policial de la dramaturgia cubana.

Este último texto ofrece en tres actos la indagación policial que se desarrolla en torno al asesinato de Rita la China, vecina del habanero barrio de Cojímar. Aparece apuñalada en su dormitorio de la humilde casa que habita junto a su hijo Rubencito. Los principales sospechosos son Rubén, su ex compañero sentimental, Mario del Castillo, un campesino que aspira a conquistarla, y Juan Méndez, vecino de la difunta, que resultará ser el verdadero asesino. El móvil principal del crimen era evitar que Rita lo denunciara por el robo de unas joyas. A esta causa primordial se unen otras motivaciones como el orgullo machista — para Juan resultaba inaceptable que una mujer le recriminara su actitud - o la codicia.

En el texto se evidencian algunas de las características que se han atribuido anteriormente a la novela policiaca revolucionaria. Por ejemplo, Rosa García, como presidenta del CDR al que pertenece Rita, colabora activamente con la Policía Nacional Revolucionaria (PNR) ofreciendo datos sobre rutinas, personas o acontecimientos de la manzana o cuadra donde viven. Del mismo modo, a pesar de que la labor del teniente García resultará crucial para resolver el caso, se nota cómo cooperan diversos miembros de las fuerzas de seguridad en su desentrañamiento, de ahí que al ser felicitado por un auxiliar, Pedro, García reste importancia a su papel y afirme: "iba a caer por los medios técnicos si le damos unos minutos más". ${ }^{23}$

21 Del Pino, Amado: Sueños del mago, Ediciones Alarcos, La Habana, 2004, pág. 95.

22 Martín, Víctor: "Teatro policiaco: Ha muerto una mujer", El Caimán Barbudo, La Habana, abril de 1976, n. ${ }^{\circ} 101$, pág. 14.

23 Fernández García, Ernesto, pág. 125. 
Otro aspecto que llama la atención es la insistencia en el rol regenerador del trabajo y su capacidad para ayudar a discernir entre "buenos" y "malos" ciudadanos. Son varias las alusiones que se encuentran a lo largo de la obra sobre la consideración que los diversos personajes merecen en sus respectivos centros laborales. Los caracteres quedan marcados por su comportamiento en el trabajo. Sin duda, el personaje más desfavorecido en este aspecto es Juan, quien representa la figura del "parásito social" (que devendrá en criminal). De hecho, a la hora de investigar a este último, el auxiliar de la PNR recurre a tres fuentes: el archivo de fichas policiales, sus relaciones de amistad y su colaboración, o mejor dicho, su escasa colaboración con su CDR, y, por último, la información que le proporcionan en su centro de trabajo, donde descubre que fue sancionado por el Consejo de Trabajo por su ausentismo y por falsear la tarjeta de entrada y salida. Junto a las realizadas contra Juan, las críticas vertidas contra Rubén nos muestran el perfil del trabajador cumplidor, pero ajeno a las labores voluntarias o a la participación en las asambleas.

Por último, el caso de Rita escenifica la salvación personal alcanzada gracias al trabajo. En este caso, lo laboral transciende sus implicaciones puramente materiales para pasar a considerarse como un mecanismo que propicia el cambio identitario. Comenzar a trabajar en una fábrica textil hace que Rita deje atrás su insana dependencia sentimental por Rubén y se aleje de la santería con cuyos poderes pretendía recuperarlo, al tiempo que entra a participar activamente en la sociedad revolucionaria, como ejemplifica su intervención en una asamblea laboral o su vinculación a la Federación de Mujeres Cubanas (FMC). De este mismo modo, empieza a solventar sus problemas de deudas. Rita comienza así a comprometerse con el modelo identitario privilegiado de la "mujer nueva", de ahí que el asesinato que Juan comete se vuelva aún más deleznable. En cualquier caso, se constata cómo los criterios laborales o de implicación en las organizaciones de masa actúan como pistas para evaluar las virtualidades delictivas de los diversos personajes.

Para concluir estas palabras dedicadas a Ha muerto una mujer, revisemos por unos instantes la visión que el texto ofrece de la santería. En primera instancia aparece como un mundo ajeno a las buenas prácticas revolucionarias, por mucho que el fiscal le comente a Rubén: “[...] no le estamos criticando aquí el que usted crea o no; lo que queremos dejar establecido es que Rita con su santería constituía una amenaza para usted y su concubina". Parece como si no se cuestionara tanto la fe, que en cualquier 
caso queda desligada de los intereses de los representantes prototípicos del poder revolucionario (miembros de la PNR o del CDR, por ejemplo), sino como que se procediera a lanzar una advertencia sobre la ineficacia de las soluciones buscadas a través de esta vía, así como de la "ralea" de algunos de sus practicantes más destacados. En este sentido, la figura de Antini, quien junto con el "padrino" ostenta la categoría de representante por excelencia de la santería, aparece caracterizado como una vulgar sacacuartos: "ANTini. Hay que buscar un gallo negro para Changó. Eso no es fácil. Porque... chivo para Ochún... ni pensarlo. ¿Dónde? Alguna palomita para Obatalá y el gallo negro para Changó. Yo creo que con ciento cincuenta pesos....". ${ }^{24}$

En relación con este punto, no está de más recordar que en el capítulo dedicado a la religión en la "Declaración del I Congreso Nacional de Educación y Cultura" se había acordado, entre otras cuestiones, que: "La revolución respeta las creencias religiosas como derecho de cada cual, así como el culto. No impone, no persigue, no reprime a nadie por sus creencias religiosas". Sin embargo, y tan sólo un poco más abajo, leemos: "Respecto a las sectas oscurantistas y contrarrevolucionarias, desenmascararlas y combatirlas". ${ }^{25}$ Presumiblemente, el texto se estaba refiriendo sobre todo a grupos como los Testigos de Jehová, el Bando Evangélico de Gedeón o los Adventistas del Séptimo Día, contra los que ya había cargado el autor líneas arriba. No obstante, y aunque no se las considere en este documento específicamente, es indudable que las religiones afro-cubanas fueron desprestigiadas y minusvaloradas por determinados representantes de la oficialidad revolucionaria, que pudieron considerarlas como prácticas contrarias al espíritu socialista.

Por su parte, Crimen en "Noche de máscaras", de Antonio Veloso y Rodolfo Pérez Valero, cuenta con un rasgo que la particulariza: la acción transcurre antes del triunfo revolucionario de 1959, concretamente en diciembre de 1949. En esta ocasión, la carga ideológica nos remite a las luchas entre ortodoxos y auténticos, por un lado, y entre sindicalistas de organizaciones como la Federación Nacional de Trabajadores Azucareros (FNTA) o la Central de Trabajadores de Cuba (CTC) contra la patronal, por otro. A partir de ahí se teje una denuncia contra un sistema político al que

24 Ibídem, págs. 107, 95-96, respectivamente.

25 "Declaración del I Congreso Nacional de Educación y Cultura", Casa de las Américas, La Habana, 1971, n. ${ }^{\text {os }} 65-66$, pág. 12. 
se le acusa de propiciar el expolio de los recursos naturales ante manos foráneas y de sustentarse en la represión y el engaño, más que en la legitimidad democrática.

Este drama ofrece una propuesta escenográfica y argumental metateatral, puesto que la acción arranca cuando el grupo Comediantes Modernos representa la obra Noche de máscaras en un teatro. Mientras transcurre la acción de este drama secundario, muere una de sus integrantes, Perla. En la sala coinciden en ese momento varias personas que ayudarán a dilucidar lo sucedido: el teniente Cuervo, miembro del Partido Ortodoxo, y el periodista Ismael Blanco, cuyos artículos sobre las luchas de los trabajadores del central azucarero Demetrio los espectadores reales han tenido la oportunidad de seguir gracias a una ingeniosa técnica que ayuda a profundizar en los objetivos ideológicos del drama: a los asistentes se les habrá entregado antes de que comience la función, con toda la anticipación que sea posible, un ejemplar del periódico Hoy, órgano de expresión del comunista Partido Socialista Popular. El contenido de este diario se adjunta a modo de apéndice en la edición que consulto, ${ }^{26}$ donde se aprecia cómo se intercalan artículos reales y ficticios, haciendo especial hincapié en presentar las huelgas y reclamaciones de los trabajadores del central Demetrio, situado en Camagüey.

Tras una serie de averiguaciones se descubre que la muerte de Perla obedece a la maniobra de un representante del Congreso por el Partido Auténtico, Ángel del Corral, "Yeyo". Perla había sido su amante, por lo que conocía sus intenciones de pactar con los representantes de la Caribbean Cane Sugar Corporation para establecer una legislación que les permitiera rebajar el diferencial azucarero ${ }^{27}$ y disminuir los salarios de los trabajadores de varios centrales, entre ellos el Demetrio. A cambio, Yeyo vería saldadas sus deudas de juego. Sin embargo, Perla decide ser fiel a su familia (su padre, Anisio Montero, había sido un inquebrantable dirigente sindical) y denunciar los tejemanejes de Yeyo, de ahí que éste se decidiera a preparar su asesinato.

26 Existe una primera edición de 1986. No obstante, aquí se citará por la de 1989.

27 Tras la Segunda Guerra Mundial se intentó congelar el precio que Estados Unidos pagaba a Cuba por su azúcar. Las movilizaciones en contra consiguieron imponer una cláusula de garantía en las negociaciones que mantuvieron al respecto ambos gobiernos. Eso hizo que se estableciera que el precio del azúcar aumentaría en la misma proporción que lo hiciera el de los productos de primera necesidad norteamericanos que importaba la isla. Así, el salario de los trabajadores azucareros, dependiente de esas cotizaciones, se incrementaría con el llamado "diferencial azucarero". 
A pesar de que la colaboración entre el periodista Blanco y el teniente Cuervo resulta fructífera, llegándose a descubrir que el asesino es el doctor que atendió a Perla en primer lugar, Yeyo no pagará por el crimen. Más bien, comprobamos cómo gracias a la connivencia de Serpa, agente enviado por el capitán Carreño, para obstaculizar el trabajo de Cuervo, y la del propio Carreño, que acude al escenario del crimen en el último momento, se aprovecha un momento de confusión para acabar con la vida de Cuervo en el propio teatro, delante de la vista de todos los asistentes a la representación de Noche de máscaras. Al momento, Carreño se encarga de ofrecer a los espectadores la versión oficial de los hechos, que será la que habrán de creer por mucho que sus propios ojos les hayan demostrado que se trata de una burda mentira:

Carreño. (A los espectadores.) Atiendan todos. Son lamentables los hechos que ustedes acaban de presenciar. Un vulgar crimen pasional ha provocado este doloroso incidente en el que ha perdido la vida uno de nuestros más sagaces y abnegados hombres, a quien, a pesar de ciertas diferencias de criterios admirábamos por su incomparable trayectoria. Así es nuestra profesión: arriesgar la vida para mantener el orden en el país, y que ustedes puedan sentirse seguros y tranquilos en el hogar al que regresarán ahora.

Es más, al acabar la función a los espectadores se les vuelve a entregar otro periódico. En esta ocasión se trata de un ejemplar del conservador Diario de la Marina, en la que se secunda la versión del crimen pasional, donde conocemos que han encontrado "suicidado" en su celda al ejecutor de Perla. Junto a estas noticias, la tendencia ideológica de la publicación se revela al dar por buenas las explicaciones de las autoridades sobre lo acontecido en el Demetrio, cuyos obreros son calificados de "revoltosos comunistas y obreros confundidos por la propaganda roja", ${ }^{28} \mathrm{o}$ al recoger sin espíritu crítico alguno las declaraciones de Yeyo, donde aparece como un político de vocación patriótica intachable.

Así pues, en Crimen en "Noche de máscaras" los miembros de los cuerpos de seguridad carecen de la honestidad que se les atribuye a sus homólogos revolucionarios en otras obras del género. Tanto Cuervo (proortodoxo) como Carreño y Serna (pro-auténticos) toman el crimen como un medio de atacar o proteger sus intereses de partido. En cambio, Ismael Blanco y Perla defienden a los verdaderos protagonistas de la obra, los trabajadores azucareros, cuya presencia se siente en todo momento, a pesar de

28 Veloso, Antonio y Pérez Valero, Rodolfo: Crimen en "Noche de máscaras", Letras Cubanas, La Habana, 1989, págs. 90, 109, respectivamente. 
que no aparecen en escena, indicando así dónde reside la fuerza que habrá de arrasar con el circo institucionalizado en el que se habría convertido la república "priista" ${ }^{29}$ según los autores. La propuesta ideológica de Veloso y Pérez Valero actúa en un doble sentido: denunciando la situación política pre-revolucionaria y destacando a los que se considera valedores del orden por llegar, es decir, codifican filias y fobias del pasado, pero con la mirada puesta en el futuro.

Con Ernesto, de Gerardo Fernández García, penetramos en el mundo del contraespionaje, donde los delitos se cometen básicamente por motivaciones políticas, con el fin último de desestabilizar o tumbar al gobierno del país enemigo. De ahí que las fuerzas que entren en juego sean los servicios secretos de las potencias en conflicto o los partidarios de acabar con el sistema imperante. Así pues, Ernesto evoca los primeros tiempos de la Revolución, cuando su estabilidad era cuestionada día tras día por medio de atentados, sabotajes y violentas injerencias foráneas. Fernández García elogia la labor de los miembros del Ministerio del Interior que consiguieron infiltrarse en las organizaciones contrarrevolucionarias y dinamitarlas desde dentro. La trama narra cómo Ignacio, agente de la Seguridad del Estado, se ve abocado a romper sus lazos familiares para infiltrarse en las filas de dichas organizaciones y ganarse el favor de la embajada estadounidense. Una vez que ha concluido su misión en la isla, y contando ya con la confianza de los norteamericanos, se le propone embarcarse en una misión extrema, de la que es posible que no regrese. Sin embargo, Ignacio no duda en ningún momento en acometerla. En el pasaje donde se confirma su decisión se aprecian lo melodramático y lo épico que resultan ser dos de los rasgos más característicos del drama:

MARIO. [...] Una misión larga. En el extranjero. Uno, dos, tres años, quizás más. Corres el riesgo... ¿Has oído hablar de El Paso? (Ignacio lo mira simplemente.) Un lugar inhóspito. Muy extenso. Allí pueden hacerte desaparecer. Te sueltan desde un helicóptero y las aves de rapiña se ocupan del resto de lo que quede de ti. (Pausa.) Y por acá, a tu regreso, suponiendo que regreses, puedes encontrarte que tu mujer se te ha casado con otro. (Pausa.) Está en su derecho. Se supone que seas un traidor. (Pausa.) Va a tener un hijo tuyo. La Jefatura sabe lo que te está proponiendo, Ignacio. Entendería una negativa tuya. Ya has hecho bastante.

IGnaCIO. (Prende un cigarro y fuma.) ¿Cómo voy a salir? $?^{30}$

29 Este adjetivo hace referencia a Prío Socarrás, presidente de la República de Cuba entre 1948 y 1952, año en el que fue derrocado por un golpe de Estado encabezado por Fulgencio Batista.

30 Fernández García, Ernesto, págs. 55-56. 
El recurso al melodrama se aprovecha con fines ideológicos, de modo que el mismo título de la obra remite tanto al propio Che Guevara como al nombre que Ignacio y su esposa, Irene, habían acordado ponerle a su hijo. Sin embargo, una vez que Ignacio se infiltra pasa a representar el papel del combatiente desengañado con el rumbo socialista que está tomando la Revolución, de ahí que se niegue a que su hijo se llame Ernesto. No obstante, esta negación inicial no hace sino propiciar que el final del drama aumente su clímax sentimental: tras unos dos años en Estados Unidos, Ignacio huye de nuevo a Cuba, antes de que lo arresten o maten, y descubre que su mujer, de moralidad revolucionaria inquebrantable, mantuvo el nombre del guerrillero argentino para su hijo.

Otro de los elementos que potencian el patetismo proviene de la figura de Rosario. Madre de Ignacio, y esposa e hija de héroes bélicos y laborales, no duda en renegar de su hijo en un monólogo en el acto III. ${ }^{31}$ De ella decía un crítico tras el estreno de la pieza:

En sentido general, en este personaje se materializa un paralelismo con Mariana Grajales, excesivamente evidenciado, cuando hubiera sido más positivo, desde el punto de vista estético, sugerirlo y que el público completara el resto. ${ }^{32}$

Mariana Grajales fue madre de los próceres Antonio y José Maceo, y personaje sumamente recurrente en el lenguaje cotidiano del cubano, siendo protagonista de comparaciones socarronas donde sale a relucir su arrojo (verbigracia: "tenerla más grande que Mariana" o "ser hija de Mariana").

Frente a este conjunto de personajes positivos, se contrapone a aquellos que pretenden acabar con la Revolución. Por supuesto, los caracteres provenientes de Estados Unidos (Frank o el agregado militar) centran sus esfuerzos en derrocar al gobierno recién instaurado. Para ello contactan, financian y proveen a los grupos insurgentes, ya se encuentren en el campo o en la ciudad. De este modo, confían a Ignacio la labor de enlazar a la contrarrevolución de estas zonas con la embajada estadounidense. Este recurso nos permite apreciar los diversos arquetipos que se perfilan entre las filas contrarrevolucionarias:

En primer lugar, el propio Ignacio representa el papel del ex combatiente contra Batista que se debate entre su anticomunismo y el recuerdo de

31 Ibídem, págs. 49-50.

32 Martín, Víctor: "Conflicto en un drama socialista", El Caimán Barbudo, La Habana, octubre-diciembre de 1976, núm. 107, pág. 15. 
que los estadounidenses, que ahora quieren ayudarle, también fueron quienes en su momento apoyaron al ex dictador. El giro socialista de la política de la Revolución quedó patente en el discurso de Fidel Castro del 16 de abril de 1961, tras el sepelio de los caídos en el ataque aéreo previo a la invasión de Playa Girón. Allí el mandatario afirmó la vocación socialista de la Revolución entre un público que exclamaba consignas como "¡Pa'lante y pa'lante, y al que no le guste que tome purgante!" o "Fidel, Krushov, estamos con los dos". ${ }^{33}$ Fue esta proclamación y el posterior rumbo que tomó el proceso revolucionario uno de los factores esenciales que determinaron que personas que habían ayudado a deponer a Batista se volvieran contra Castro, como evoca el caso del Mario de Aquí del G-2 soy yo, quien aboga por "una revolución nacionalista, sin Fidel y sin los americanos", ${ }^{34}$ pero que enseguida se ve enfrentado por Mustelier, partidario de la intervención estadounidense.

La oposición del contrarrevolucionario al nuevo gobierno se suele basar en estos textos en dos motivaciones básicamente: existen aquellos que se mueven sobre todo por convicciones ideológicas, y esos otros que, aunque detesten el socialismo, pretenden utilizar la lucha como un medio para medrar cueste lo que cueste. Como ejemplo de este último tipo se podría recordar la figura de Tomasito, cuyo egoísmo atestiguan estas palabras:

Tomasito. [...] ¡Qué me importa a mí la gente! ¡Que no echen hijos al mundo, que no los tengan! El mundo es de los fuertes, de los inteligentes. Mira, cuando Dios le dio inteligencia a unos y no se la dio a otros él sabía que esto iba a pasar. Así que eso es así, porque así es el mundo, no te quemes la cabeza. Unos abajo y otros arriba.

Por otro lado, el dramaturgo aprovecha para poner en boca de Hilario, uno de los jefes de los anti-castristas, algunas de las acusaciones lanzadas en aquel momento contra el nuevo gobierno y contra la Unión Soviética, que dan fe de la histeria desatada por la paranoia "roja":

HILARIO. La familia, que es sagrada en la democracia, desaparece en el comunismo. ¡Desaparece la propiedad privada; tú en el comunismo, no eres dueño ni del cepillo con que te lavas los dientes! Eso hay que decírselo al cubano. Que sepa lo que le espera si no despierta. Hablarle de que no va a pasar mucho tiempo antes de que se pase-

33 Castro, Fidel: "Discurso pronunciado en las Honras Fúnebres de las Víctimas del Bombardeo a distintos puntos de la República, efectuado en 23 y 12, frente al Cementerio de Colón, el día 16 de abril de 1961", http://www.cuba.cu/gobierno/discursos (23.de septiembre de.2008). pág. 39.

34 Fernández García, Gerardo: Aquí del G-2 soy yo, Ediciones Unión, La Habana, 1981, 
en por las calles de La Habana las tropas rusas, de que la bandera va a desaparecer, que la van a cambiar por la roja de los rusos. Y que la tierra... Esto, para los campesinos. Que la tierra fértil nuestra la están recogiendo para llevársela para Rusia, porque la tierra de allá es mala. ${ }^{35}$

Un defecto que se les suele atribuir a estos personajes es su escasa confianza en el pueblo cubano para prosperar por sí mismo, asumiendo que sin la tutela de los estadounidenses acabarán cayendo en vicios como la vagancia o el puro egoísmo, o lo que es peor, el comunismo. Se trata de los "vendepatrias":

PedRito. [...] Porque mentira, chico, mira, somos cubanos y al cubano le ha gustado siempre vivir bien, tener su buena ropa, fumarse sus buenos tabacos, rodar un carro grande y trabajar poco, ¿eh? Que no me vengan ahora con cuentos de camino.

$[\ldots]$

HILARIO. [... ] Yo te digo una cosa, sin los americanos no paramos cabeza. Si nos dejamos llevar por sentimentalismos... Así que tú decides: o Cuba libre con la ayuda de los americanos o el comunismo. ${ }^{36}$

La figura del contrarrevolucionario rural - etiquetada por la Cuba revolucionaria con el término despectivo "bandido"- fue llevada a las tablas en no pocas ocasiones por la dramaturgia cubana desde mediados de la década de 1960 y la de 1970. En este sentido, destacan obras como Unos hombres y otros (adaptación del libro homónimo de relatos de Jesús Díaz), El juicio (Gilda Hernández) y La emboscada (Roberto Orihuela), ${ }^{37}$ que reviven y toman partido ante el conflicto conocido como la "lucha contra bandidos", que enfrentó a las fuerzas revolucionarias contra la insurgencia rural hasta mediados de los sesenta, sobre todo en zonas como la Sierra del Escambray. Fernández García retoma el tipo del "bandido" y ahonda en algunos de los rasgos que lo habían caracterizado, destacando particularmente la crueldad, al tiempo que enfrenta su acción criminal a la eficiencia de las tropas revolucionarias, que salen reforzadas tras el choque con el enemigo interno:

BANDIDO. Era uno de los que manda en la cooperativa, estaba en la lista del jefe. "Mira, viejo de mierda, yo no te puedo llevar con el jefe porque está muy lejos, ni puedo hacer bulla porque la Milicia está cerca. Agáchate aquí, que con el machete te

35 Ibídem, págs. 27, 14-15, respectivamente.

36 Ibídem, págs. 11, 21, respectivamente.

37 Estas piezas se pueden encontrar en el volumen preparado por Rine Leal denominado: Lucha contra bandidos, Letras Cubanas, La Habana, 1983. 
voy a cortar la cabeza". Al otro día ya le había salido toda la sangre, la cogí por el pelo y se la llevé a Domingo. ¡Oiga, habanerito, parecía que habíamos matado al mismísimo Fidel: nos estuvieron corriendo día y noche, cercos van y cercos vienen! ${ }^{38}$

De modo que tanto en Ernesto, como en Aquí del G-2 soy yo, Fernández García ofrece un panorama de los diversos tipos de contrarrevolucionarios, animalizándolos, considerándolos indignos de llamarse cubanos, expulsándolos del solar patrio, en fin.

En Aquí del G-2 soy yo asistimos al desarrollo del enigma típico de lo policiaco (“¿quién es el culpable?") en un escenario también usual en este tipo de creaciones: el espacio cerrado, que limita considerablemente los movimientos de los protagonistas. Se trata de descubrir al traidor infiltrado dentro de una célula contrarrevolucionaria. Los fracasos dentro de la organización anti-castrista se acumulan, de ahí que sus integrantes se decidan a descubrir si hay un topo. La pieza sirve para identificar las distintas clases de contrarrevolucionarios: el ex concejal en tiempos de Batista (Adolfo), el ex combatiente anti-batistiano (Mario), el guajiro que, a pesar de que su familia se ha visto beneficiada por la Reforma Agraria, aspira a mayores logros materiales uniéndose a la contrarrevolución, el lumpen (Mustelier) o el ex dirigente de la organización anti-castrista, ahora retirado y controlado por el G-2 (Javier).

Sin embargo, el que quizás sea el rasgo más significativo del drama se aprecia una vez que se resuelve el enigma identitario: al final descubrimos que había dos agentes secretos infiltrados (Víctor y Magdalena). Hasta ese momento habían conseguido desarticular los principales planes y contactos de la célula, pero acaban desenmascarando a Víctor. No obstante, la inesperada acción de Magdalena salva la vida de su compañero y posibilita la detención de los contrarrevolucionarios. Magdalena destaca como un personaje que ha evolucionado desde posiciones burguesas hasta un intenso compromiso revolucionario gracias, entre otros factores, al trabajo en el Ministerio de Industria junto con el Che, como ella misma comenta. ${ }^{39}$

La presencia de la mujer en roles protagónicos y activos en la dramaturgia cubana era por aquel entonces cada vez más visible. Considerada como un elemento primordial para el sostenimiento de la Revolución, desde los primeros momentos que siguieron al triunfo del 1 de enero de 1959 se proyectaron medidas para mejorar su situación. Así, ese mismo día y en

38 Fernández García, Aquí del G-2, pág. 53.

39 Ibídem, pág. 120. 
el parque Céspedes de Santiago de Cuba, Fidel Castro hizo referencia a la necesidad de acabar con la discriminación femenina, refiriéndose sobre todo a los ámbitos laboral y militar. ${ }^{40}$ Más adelante, esta preocupación por los derechos femeninos sería encauzada institucionalmente al fundarse la Federación de Mujeres Cubanas (FMC), donde se aunaron políticas de género con una ideología pro-revolucionaria. En cuanto al mundo teatral, citaré tan sólo un hecho significativo: las tres piezas galardonadas (ganadora y menciones) en el premio nacional de dramaturgia José Antonio Ramos de 1975 se centraron en la temática mujer y mundo laboral (Memorias de un proyecto, de Maité Vera; Un pelo en plena juventud, de Felipe Oliva y Ramona, de Roberto Orihuela). ${ }^{41}$ Comprobamos de este modo cómo la elección de Magdalena como heroína del drama no podía ser más oportuna, demostrando que la nueva mujer revolucionaria estaba dispuesta a arriesgar todo lo que hiciera falta para mantener el status quo socialista.

\section{Escribir/abatir: epílogo}

Estamos ante un teatro que se sabe respetado y respaldado por el poder político-cultural, quien lo estimula y ayuda a su divulgación, y no sólo a través de los certámenes literarios, sino gracias a su difusión por otros cauces. Arriba ya se hizo referencia a la intención del ICR de grabar y reproducir obras de Fernández García. En cuanto al caso concreto de Ernesto, sabemos que fue adaptada a la televisión por Abel Ponce, según afirmaba el crítico Víctor Martín. ${ }^{42}$. Asimismo, a través de la creación de nuevos colectivos como, por ejemplo, el Grupo de Teatro Político Bertolt Brecht, se fortalecía la presencia en el panorama nacional de obras con una temática eminentemente política. De este modo, esta compañía en concreto pretendía revisar desde un punto de vista marxista ciertos momentos de la historia — sobre todo contemporánea—, relacionados con "la lucha de

40 Castro, Fidel: "Discurso pronunciado por el doctor Fidel Castro Ruz, en el Parque Céspedes, de Santiago de Cuba, el primero de enero de 1959", http://www.cuba.cu/gobierno/ discursos/1959/esp/f010159e.html (14 de noviembre de 2008).

41 Las referencias bibliográficas de estas obras son: Vera Maité: Memorias de un proyecto, UNEAC, La Habana, 1976; Oliva, Felipe y Orihuela, Roberto: Un pelo en plena juventud. Ramona, Ediciones Unión, La Habana, 1978.

42 Martín, Víctor: "Conflicto en un drama socialista”, El Caimán Barbudo, La Habana, 1976, n. ${ }^{\circ} 107$, pág. 15 . 
los pueblos del mundo". ${ }^{43}$ Así quedó patente en sus mismos inicios, al estrenar Juan Palmieri, del uruguayo Antonio Larreta, en febrero de 1973. Esta pieza rendía un homenaje al movimiento guerrillero tupamaro y, previamente, había conseguido hacerse con el premio de teatro de la Casa de las Américas en su edición de 1972.

Por su parte, Santiago Esteso, en las páginas finales de su volumen dedicado a la narrativa policial cubana (Ficciones en las fronteras de la ley), critica el proyecto de regulación ciudadana que se desprende de determinadas obras del género, afectando no sólo a la disidencia política, sino también, y ahí es donde sitúa su foco de atención, a la otredad sexual. Para decirlo con sus propias palabras:

El poder revolucionario se valió, entre otros recursos, del género policial para propiciar un entramado de textos que sirvieran de registro, control y normalización de los habitantes de la nación. Un tejido de historias que supuso la puesta en narración y la producción de ciudadanos bajo los epígrafes de "buenos" o "malos" sujetos. En esta operación, la categoría "delito" sirvió para decidir quiénes merecían habitar la nueva sociedad y quiénes debían ser identificados y expulsados como sus malditos parias. $^{44}$

Este carácter eugenésico del género hizo que, en cuanto a la dramaturgia, los objetivos ideológicos que se perseguían convirtiesen a estos textos en maquinarias letradas de denuncia, por un lado, y de legitimación, por el otro. Los enemigos de la Revolución son mostrados indefectiblemente como elementos decididos a perturbar la construcción de un proyecto colectivo esperanzado. De ahí que estas piezas teatrales actúen con la precisión de un fusil con mira telescópica, decididas a identificar y abatir a aquellos que se oponen decididamente a los designios gubernamentales, sobre todo, a los que pretenden servirse de la violencia directa contra el Estado y aceptan la colaboración del "monstruo" martiano. La legitimidad del proyecto revolucionario se extiende en el tiempo gracias a Crimen en "Noche de máscaras". Paralelamente, con obras como Ernesto o Aquí del G-2 soy yo se mina la credibilidad de las fuerzas contrarrevolucionarias, ofreciéndolas como una alternativa sádica y "vendepatria", "gusana" ${ }^{45}$ en

43 Garzón Céspedes, Francisco: “Juan Palmieri, tupamaro”, El Caimán Barbudo, La Habana, 1973, n. ${ }^{\circ} 69$, págs. 14-15.

44 Esteso, Santiago: Ficciones en las fronteras de la ley, Universidad Complutense de Madrid, Madrid, 2004, págs. 146-147.

45 Desde la óptica pro-gubernamental, aquellos cubanos que persiguen la instauración de un gobierno no revolucionario son denominados recurrentemente "gusanos" o "gusanera". 
fin. Por último, Ha muerto una mujer marca algunos de los nuevos valores ciudadanos privilegiados en el estado socialista, mientras que reformula el campo de los defectos, relacionándolos con el incumplimiento de las nuevas tareas revolucionarias, enfocadas a cumplir las expectativas patrias, igualadas ambas desde el poder político.

Presentado el 24 de septiembre de 2008 Aceptado el 18 de noviembre de 2008 